Jansen, J., Butow, P.N., Weert, J.C.M. van, Dulmen, S. van, Devine, R.J., Heeren, T.J., Bensing J.M., Tattersall, M.H.N. Does age really matter? Recall for medical information in cancer patients. Journal of Clinical Oncology: 2008, 26(33), 5450-5457

\begin{tabular}{|l|l|}
\hline Postprint Version & 1.0 \\
\hline Journal website & $\underline{\text { http://jco.ascopubs.org/cgi/reprint/JCO.2007.15.2322v1 }}$ \\
\hline Pubmed link & $\underline{\text { http://www.ncbi.nlm.nih.gov/pubmed/18936478 }}$ \\
\hline DOI & $10.1200 /$ JCO.2007.15.2322 \\
\hline
\end{tabular}

This is a NIVEL certified Post Print, more info at http://www.nivel.eu

\title{
Does age really matter? Recall of information presented to newly referred cancer patients
}

\author{
JesSe JANSEN $^{1 *}$, Phyllis N. Butow ${ }^{2}$, Julia C.M. VAN WeERT ${ }^{3}$, SANDRA VAn Dulmen ${ }^{1}$, \\ RHONDA J. DEVINE ${ }^{2}$, THEA J. HEEREN ${ }^{4}$, JOZIEN M. BENSING ${ }^{1,5}$, MARTIN H.N. \\ TATTERSALL ${ }^{2}$, \\ ${ }^{1}$ NIVEL (Netherlands Institute for Health Services Research), Utrecht, The Netherlands \\ ${ }^{2}$ Medical Psychology Research Unit, School of Psychology/Department of Cancer Medicine, \\ University of Sydney, Sydney, Australia \\ ${ }^{3}$ The Amsterdam School of Communications Research (ASCoR), University of Amsterdam, \\ Amsterdam, The Netherlands \\ ${ }^{4}$ Symfora Group, Centers for Mental Health Care, Amersfoort, The Netherlands \\ ${ }^{5}$ Department of Health Psychology, Utrecht University, Utrecht, The Netherlands
}

*Correspondence to: Jesse Jansen NIVEL

P.O. Box 1568

3500 BN UTRECHT

The Netherlands

E-mail: j.jansen@nivel.nl

Phone: +31 (0) 302729828

Fax: +31 (0) 302729729

\begin{abstract}
Purpose. To examine age- and age-related differences in recall of information provided during oncology consultations.

Patients and methods. 260 cancer patients with heterogeneous cancers, seeing a medical or radiation oncologist for the first time, participated in the study. Patients completed questionnaires assessing information needs and anxiety. Recall of information provided was measured using a structured telephone interview in which patients were prompted to remember details physicians gave about diagnosis, prognosis, and treatment. Recall was checked against the actual communication in audio-recordings of the consultations.
\end{abstract}

Results. Recall decreased significantly with age, but only when total amount of information presented was taken into account. This indicates that if more information is discussed, older patients have more trouble remembering the information than younger ones. In addition, recall was selectively influenced by prognosis. First, patients with a poorer prognosis recalled less. Next, the more information was provided about prognosis, the less information patients recalled, regardless of their actual prognosis. 
Conclusion. Recall is not simply a function of patient age. Age only predicts recall when controlling for amount of information presented. Both prognosis and information about prognosis are better predictors of recall than age. These results provide important insights into intervention strategies to improve information recall in cancer patients

\section{INTRODUCTION}

During oncology consultations, patients are confronted with detailed information about their disease and treatment ${ }^{1}$ that is often difficult to understand and remember. ${ }^{2,3}$ Previous studies have shown that patients forget substantial amounts of the provided information. ${ }^{2,4-6}$ Due to age-related cognitive changes, recall may be even more taxing for older patients which is likely to affect medical compliance and outcomes. ${ }^{7}$

Cancer is largely a disease of older age; more than one half of all new cases and almost two thirds of the deaths from cancer in the US occur among the $13 \%$ of the population that is aged 65 years and older (hereinafter referred to as "older" patients). ${ }^{8}$ Aging has been associated with decreases in speed of information processing ${ }^{9}$ and working memory performance. ${ }^{10,11}$ In addition, age-related conditions like sensory deficits ${ }^{12,13}$ and health problems ${ }^{14}$ reduce memory function.

On the other hand, older people's substantial knowledge and experience may weaken the impact of reductions in cognitive resources. ${ }^{7,14}$ Besides, older people are better able to regulate their emotions ${ }^{15}$ which might also compensate for negative age effects on cognition and information recall. ${ }^{16}$ Moreover, there is a growing body of literature that has demonstrated the importance of variables other than chronological age such as functional-, psychological- and physical status in determining which patients do well and which patients do poorly in oncology settings. ${ }^{17-20}$ Similarly, these variables may impair patients' recall, over and above the effects of age.

Literature on medical information processing in healthy adults nonetheless indicates that older adults have more difficulties remembering and following physicians' instructions. ${ }^{21}$ Studies conducted in clinical settings show mixed results. ${ }^{22-28}$ Variance of several study characteristics may have contributed to these discrepancies. For example, age differences in recall might be influenced by age differences in patient-physician communication. It is known that information that is tailored to patients' needs is better remembered. ${ }^{29}$ Patients who actively participate in consultations are better able to direct the information flow ${ }^{30}$, and consequently, they may also recall more. This is especially relevant as studies indicate that older patients participate less in consultations and ask fewer questions ${ }^{31,32}$ although others report that participation is not related to age ${ }^{33,34}$ Finally, there are small age differences in the type and amount of information cancer patients' value. ${ }^{35,36}$ While the majority of older patients want as much information as possible about diagnosis and treatment, they often do not wish to be told all details about, for example, prognosis ${ }^{36}$.

It is essential to understand if and how age affects recall of information, because older cancer patients should have sufficient comprehension to make informed choices and correctly follow treatment regimens. Several studies have focussed on Comprehensive Geriatric Assessment (CGA), including investigations of cognition and the impact of cognitive dysfunction on care. ${ }^{18}$ However, little is known specifically about recall of information in older cancer patients. 
To ensure good quality of care for the growing group of older cancer patients, effects of age have to be investigated while recognizing the heterogeneity of these patients. ${ }^{17}$ In this study, we therefore explored if age is associated with recall of information presented to cancer patients while at the same time looking at the importance of age-related factors (e.g. anxiety, ECOG performance status ${ }^{37}$ and prognosis), information preferences and patients' active involvement in the consultation.

\section{PATIENTS AND METHODS}

This study was part of a larger project investigating the effects on patients' question-asking triggered by a question prompt sheet (QPS) administered immediately before the first consultation with an oncologist in combination with active endorsement and systematic review of questions by the physician. (30) Patients in the study were randomised to one of three conditions (passive physician + QPS; active physician + QPS; no QPS). The aim of the larger project was to determine if the question prompt sheet increased question-asking behaviour and to investigate the effect of increased question asking on psychological outcomes.

This project received ethics approval from the Central Sydney Area Health Service, Western Sydney Area Health Service and the University of Sydney Ethics Committees.

\section{Participants}

Consecutive patients with heterogeneous cancers, attending an initial consultation with one of five medical and four radiation oncologists at two university hospital outpatient clinics in Australia, were invited to participate. Exclusion criteria were; (i) age less than 18 years, (ii) non-English speaking, (iii) advanced incapacity, (iv) life-threatening illness other than cancer, and (v) non availability for follow up.

\section{Procedure}

Before the consultation, patients were informed of the study's purpose and requirements and permission was sought to audiotape the consultation. After providing written consent, participants completed two short questionnaires measuring anxiety and information needs and preferences.

\section{Coding}

Patient participation was measured by counting the number of questions (requesting information or guidance) asked during the consultation. Consultation length was timed as was the number of times the physician and patient spoke ('events'). We also calculated patients' relative contribution to the conversation (patient events / total patient and physician events).

A coding manual was developed with which two coders were trained. Coders re-coded a random $10 \%$ of their own consultations and $10 \%$ of the other's consultations to determine intra- and inter-rater reliability (Cohen's Kappa), which was 0.95 and 0.92 , respectively.

\section{Measures}

\section{Anxiety}

Anxiety was measured using the 20-item Spielberger State Anxiety Scale. ${ }^{38}$ Respondents indicated their level of agreement (from 'strongly agree' to 'strongly disagree' on a 4-point Likert scale) to each of the items, with raw scores summed to produce a total score (20-80) 
Jansen, J., Butow, P.N., Weert, J.C.M. van, Dulmen, S. van, Devine, R.J., Heeren, T.J., Bensing J.M., Tattersall, M.H.N. Does age really matter? Recall for medical information in cancer patients. Journal of Clinical Oncology: 2008, 26(33), 5450-5457

and higher values representing higher levels of anxiety. This scale is used widely in cancer populations ${ }^{39}$. Cronbach's alpha for this scale was .936 .

\section{Information needs and preferences}

Participants indicated the amount of information they wanted about seven aspects of their disease using the Information Styles Questionnaire ${ }^{40}$ rated on a 5-point Likert scale ('absolutely want no more' to 'want a great deal more'). Item scores were summed to produce a measure of information needs (7-35). Cronbach's alpha for this scale was .897. Information preference was assessed using two items derived from the same questionnaire. Questions addressed preferred amount of information (3-point Likert scale) and detail (5point Likert scale). Because of the highly skewed distribution, scores on the information question were dichotomized into 'prefer all information' (score 3 ) and 'do not prefer all information' (scores $1 \& 2$ ). Likewise, scores on the detail question were dichotomized into 'prefer as many details as possible' (score 5) and 'do not prefer as many details as possible' (score 1-4).

\section{Recall}

Recall was measured using a structured telephone interview with open-ended questions ${ }^{4}$ within ten days after the consultation. Patients were prompted to remember details physicians gave about diagnosis (e.g. cancer site, extent), prognosis (e.g. chances of cure, life expectancy), and treatment (e.g. type of regimen, side effects). Each item recalled by the patient during the telephone interview was recorded and compared with the items mentioned by the oncologist during the audio taped consultation. The number and percentage of facts recalled accurately in total and for each category separately were calculated. To standardize recall in relation to the amount of information discussed in the consultations, we used percentage recall as the outcome.

\section{Medical details}

Physicians provided medical details for each patient enrolled in the study, including, treatment intent (curative, adjuvant, or palliative), estimated prognosis (months, years, normal life expectancy) and ECOG performance status, an assessment of the of disease progression and daily living abilities of a patient ranging from 0 (fully active) to 5 (dead). ${ }^{37}$

\section{Statistical analysis}

$X^{2}$ tests and independent samples $t$-tests, as appropriate, were used to compare patients who filled out the recall questionnaire to those who did not, as well as to compare younger patients $(<65)$ to older patients $(\geq 65)$.

Multiple regression analysis was used to examine predictors of percentage recall. The following six sets of variables were entered as separate blocks; (i) background characteristics, (ii) age (continuous) and age-related variables, (iii) information needs, (iv) patient participating level, (v) consultation characteristics, (vi) interaction terms (i.e. age $\times$ variable). The analysis revealed a quadratic, rather than linear, relationship between percentage recall and the total amount of information presented. To account for this nonlinearity, we used a second-order polynomial regressor (quadratic) for this variable. ${ }^{41}$ Throughout, type of intervention and whether or not the patient had listened to an audiotape of the consultation prior to the recall test was controlled for. All continuous variables were mean centred. As information preferences were uniformly quite high without variability, these were not used as a variable in the above analyses. All analyses were conducted using SPSS (version 14.0; SPSS Inc, Chicago, Ill) and results were considered significant when $\mathrm{p}<.05$. 
Jansen, J., Butow, P.N., Weert, J.C.M. van, Dulmen, S. van, Devine, R.J., Heeren, T.J., Bensing J.M., Tattersall, M.H.N. Does age really matter? Recall for medical information in cancer patients. Journal of Clinical Oncology: 2008, 26(33), 5450-5457

\section{RESULTS}

\section{Patient characteristics}

Three hundred and forty-nine patients were considered eligible for the larger study to which 318 consented (91\%). Patients who refused participation most commonly reported feeling too anxious; others were not interested or reported feeling too ill. Of the 318 patients who participated in the larger study, 260 patients $(82 \%)$ completed the recall interview and comprised the subsample for this study. Patients without a recall interview were more likely to have received a QPS with an active physician $(39.7 \%$ versus $22.3 \%$ ), and less likely to have received a QPS with a passive physician $(15.5 \%$ versus $26.9 \%)$ or be in the control group $\left(44.8 \%\right.$ versus $\left.50.8 \%, \chi^{2}(2)=8.42, \mathrm{p}<.05\right)$. No other demographic and disease differences between those with a recall interview and those without were found. Participant characteristics are shown in Table 1.

\section{[TABLE 1]}

No age differences in information needs or preferences were found. Most patients wanted all information and details, regardless of age. Younger patients did ask more questions (mean=12.6, $\mathrm{SD}=9.6$, range $0-53$ ) than older patients (mean=9.8, $\mathrm{SD}=9$, range $0-50 ; \mathrm{p}<.01$ ). However, no age difference was found in patients' relative contribution to the encounter.

\section{Presentation and recall of information}

Mean consultation length was significantly higher for younger patients (31.9 minutes, $\mathrm{SD}=13.8$, range 7.8-70.0) than for older patients (28.0 minutes, $\mathrm{SD}=12.3$, range 9.8-72.6, $\mathrm{p}<0.05$ ). No significant age differences regarding total amount of information presented and total percentage recall were found (see Table 2).

\section{[TABLE 2]}

\section{Predictors of information recall}

The final regression model including all predictor variables (Table 3 ) was significant and accounted for $29 \%$ of the variance in recall $(\mathrm{p}<.001)$. Age $(\beta=-.165, \mathrm{p}<.05)$, prognosis (years: $\beta=-.245, p<.05$; weeks to months: $\beta=-.324, p<.01$ ), amount of information presented $(\beta=-.191, p<.05$; quadratic component: $\beta=.157, \mathrm{p}<.05)$ and consultation duration $(\beta=-.307, p<.01)$ all significantly predicted recall.

\section{[TABLE 3]}

\section{Contribution of variable blocks}

There was no influence of the background variables gender and level of education on recall $\left(\Delta \mathrm{R}^{2}=.02\right.$, n.s. $)$ and this remained the same in all subsequent blocks.

The block with age-related variables was significant and accounted for $11 \%$ of the variance in recall $(\mathrm{p}<.01)$. Prognosis was a significant predictor, whilst chronological age, ECOG performance status, treatment intent and anxiety were not. Patients with an estimated prognosis of years $(\beta=-.302, p<.01)$ or weeks to months $(\beta=-.463, p<.001)$ had lower recall scores compared with patients with normal life expectancy (see also Table 4). Prognosis remained a significant predictor of recall in subsequent blocks.

The next block, containing information needs, did not influence recall $\left(\Delta \mathrm{R}^{2}=.01\right.$, n.s. $)$, and this remained the case throughout.

Adding the block with the participating behaviour variables did influence recall $\left(\Delta \mathrm{R}^{2}=.03\right.$, $\mathrm{p}<.05)$. Number of patient questions significantly predicted recall $(\beta=-.198, \mathrm{p}<.01)$; the more questions patients asked, the less they recalled. Relative patient contribution did not influence recall; this remained the same in all subsequent blocks. 
Jansen, J., Butow, P.N., Weert, J.C.M. van, Dulmen, S. van, Devine, R.J., Heeren, T.J., Bensing J.M., Tattersall, M.H.N. Does age really matter? Recall for medical information in cancer patients. Journal of Clinical Oncology: 2008, 26(33), 5450-5457

The final block containing consultation characteristics was significant and accounted for $10 \%$ of the variance in recall $(\mathrm{p}<.001)$. Total amount of information presented $(\beta=-.191$, $\mathrm{p}<.05$; quadratic component: $\beta=.157, \mathrm{p}<.05)$ and consultation duration $(\beta=-.307, \mathrm{p}<.01)$ were both significant predictors of recall; recall was lower after longer consultations and when more information was presented. The positive quadratic component shows that the decrease in recall slows down when the highest amounts of information are presented. Furthermore, introducing these variables revealed a negative association between age and recall $(\beta=-.165$, $\mathrm{p}<.05$ ). This indicates that recall did decrease with age but that this effect was suppressed by differences in consultation length and the amount of information presented in consultations with patients from different ages. Finally, the effect of number of patient questions disappeared ( $\beta=-.002$, n.s.) when the block with consultation characteristics was introduced. None of the interactions between age and the other variables were significant.

\section{Exploring type of information}

As recall of information was negatively associated with prognosis, we tested the hypothesis that prognosis does not matter but rather, it is the emphasis that is put on prognosis in the consultation that does matter. Therefore, the amount of information presented about prognosis and the other information categories (diagnosis and treatment) were added to the final model, with separate regressions conducted for each category. The number of prognosis items presented significantly predicted recall $(\beta=-.214 p<.01)$, explaining $3 \%$ of the variance in recall $(p<.01)$. This suggests that the more prognosis information presented, the less information patients recalled. Number of diagnosis and treatment items did not predict recall. This effect could not be explained in terms of levels of anxiety. Introducing the number of prognosis items discussed did not influence any of the other effects.

\section{[TABLE 4]}

\section{DISCUSSION}

Our analysis revealed that younger and older patients correctly recalled $49.5 \%$ and $48.4 \%$ of the information, respectively. It is difficult to compare recall rates found in different studies, because of variance in study characteristics (e.g. recall assessment methods). Nevertheless, this resembles the results of other studies showing that, regardless of age, cancer patients forget substantial amounts of information. ${ }^{4-6,42}$

Age significantly decreased recall of information but this effect was only present when consultation length and total amount of information presented were taken into account. Apparently, if consultations are longer and if more information is presented, older patients have more trouble remembering information. Physicians seemed to have anticipated this effect by adjusting the amount of information they presented according to age. Also, older patients asked fewer questions than younger patients. And contrary to our expectations, the more questions patients asked, the less they recalled. However, this effect disappeared when controlling for consultation length and amount of information presented.

More importantly, our study revealed that estimated prognosis predicted recall. Patients with a poorer prognosis consistently remembered less information than patients with a better prognosis. Perhaps not surprisingly, these results indicate that recall is not simply a function of chronological age, but rather a more complicated outcome. This is supported by the fact that although the variables in our model explained a substantial amount of the variation in recall (29\%), a larger part remained unexplained. Clearly, other factors, for instance cognition and frailty, have to be explored to completely understand the mechanisms underlying information recall. 
Jansen, J., Butow, P.N., Weert, J.C.M. van, Dulmen, S. van, Devine, R.J., Heeren, T.J., Bensing J.M., Tattersall, M.H.N. Does age really matter? Recall for medical information in cancer patients. Journal of Clinical Oncology: 2008, 26(33), 5450-5457

It is unclear why and how patient prognosis predicts recall. Perhaps patients with a more advanced disease forget information to maintain a positive spirit. ${ }^{43}$ Even though many patients want to be fully informed, more vulnerable patients, including patients with a poorer prognosis, seem less likely to want to know every detail of their disease and treatment. ${ }^{44}$ Confronting patients with information they do not want is often not effective, as they will not remember it. ${ }^{45}$ Gattellari and colleagues ${ }^{23}$ found that denial plays a role in misunderstanding information provided by oncologists. Mechanisms of denial may act to block news perceived as threatening; similarly denial may be a mechanism to explain poorer recall in patients with a poorer prognosis as found in this study. Indeed, there is evidence that people with a repressive coping style remember less information than nonrepressors. ${ }^{46,47}$ A review on denial in cancer patients showed that denial is more frequent in older patients and in patients in a more progressing stage of their disease. ${ }^{48}$ The relation between denial, prognosis and recall seems evident, but more research is needed to disentangle the mechanisms involved.

In general, patients do not hear much of what is said after bad news is delivered. ${ }^{49} \mathrm{We}$ therefore explored the hypothesis that it is not prognosis as such, but rather discussing prognosis that impedes patients' recall. Interestingly, the more prognosis information was provided, the less information patients recalled, regardless of their actual prognosis. Although it is not exactly clear how patients conceptualize 'bad news ${ }^{43}$, prognosis information may be associated with the risk of death and disease recurrence, inducing negative emotions. ${ }^{50}$ Other studies have found that negative emotions result in attentional narrowing ${ }^{51}$, perhaps explaining the effect of prognosis information on recall.

Communicating prognosis requires careful tailoring to individual patient's preferences for more or less information and balancing the needs for clear information while maintaining hope. ${ }^{43,52}$. Recently, methods have been proposed to assist physicians with this clearly demanding task. ${ }^{53}$

Our study is limited by the fact that we did not measure patients' cognitive function ${ }^{54}$. However, the similar results for recall in younger and older patients do not make it likely that cognitive disorders played an important role in this study. In addition, our definition of older patients $(\geq 65)$ may be challenged. In future studies, it might therefore be worthwhile to include measures that detect older patients who are especially vulnerable, for instance frailty assessments or geriatric screening tools. ${ }^{17}$ Also, it is important to use prompts when measuring recall. Originally, we measured recall by simply asking patients what the physician had said (free recall). Since this resulted in very low recall scores, we had to prompt patients to remember information.

In this study, more than half of the provided information was forgotten. Older patients were particularly vulnerable to information overload. However, our results also clearly suggest that 'the frail are not always the elderly" ${ }^{55}$ as a poorer prognosis seems to reduce recall of information independent of age. There is a substantial body of literature on how to improve recall. Suggestions are to tailor information to patients' needs, ${ }^{29}$ prioritize to the most important, personally relevant information, ${ }^{16}$ organize and categorize, ${ }^{3}$ repeat ${ }^{56,57}$ and summarize the most relevant information and review it on subsequent visits ${ }^{58}$, use simple language ${ }^{16}$ and provide written materials ${ }^{16}$ or audio-recordings ${ }^{59,60}$ for later referral. More research is necessary regarding the complex interaction of wanting to know and not wanting to know (denial) and the influence of the emotional context. 
Jansen, J., Butow, P.N., Weert, J.C.M. van, Dulmen, S. van, Devine, R.J., Heeren, T.J., Bensing J.M., Tattersall, M.H.N. Does age really matter? Recall for medical information in cancer patients. Journal of Clinical Oncology: 2008, 26(33), 5450-5457

\section{ACKNOWLEDGEMENTS:}

We thank the patients and physicians who participated in this study. Furthermore, we would like to acknowledge The Dutch Cancer Society, The René Vogels Foundation, and The Netherlands Organization for Scientific Research for funding this project and Ben Colagiuri and Peter Spreeuwenberg for useful statistical suggestions.

\section{REFERENCES}

1. Eggly S, Penner L, Albrecht TL, et al: Discussing bad news in the outpatient oncology clinic: rethinking current communication guidelines. J Clin Oncol 24:716-719, 2006

2. Dunn J, Steginga SK, Rose $P$, et al: Evaluating patient education materials about radiation therapy. Patient Educ Couns. 52:325-332, 2004

3. Ley P: Memory for medical information. Br J Soc Clin Psychol 18:245-256, 1979

4. Dunn SM, Butow PN, Tattersall MHN, et al: General Information Tapes Inhibit Recall of the Cancer Consultation. J Clin Oncol 11:2279-2285, 1993

5. Bakker DA, Blais D, Reed E, et al: Descriptive study to compare patient recall of information: nurse-taught versus video supplement. Can Oncol Nurs 9:115-120, 1999

6. Jansen J, van Weert J, van Dulmen S, et al: Recall in older cancer patients: measuring memory for medical information. Gerontologist, in Press

7. Brown SC, Park DC: Theoretical models of cognitive aging and implications for translational research in medicine. Gerontologist 43:57-67, 2003

8. SEER Cancer Statistics Review, 1975-2004

9. Salthouse TA: The processing-speed theory of adult age differences in cognition. Psychol Rev 103:403-428, 1996

10. Bopp KL, Verhaeghen P: Aging and verbal memory span: a meta-analysis. J Gerontol B Psych Sci Soc Sci 60:223-233, 2005

11. Grady CL, Craik FI: Changes in memory processing with age. Curr Opin Neurobiol 10:224-231, 2000

12. Baltes PB, Lindenberger U: Emergence of a powerful connection between sensory and cognitive functions across the adult life span: a new window to the study of cognitive aging? Psychol Aging 12:12-21, 1997

13. Valentijn SA, van Boxtel MP, van Hooren SA, et al: Change in sensory functioning predicts change in cognitive functioning: results from a 6-year follow-up in the maastricht aging study. J Am Geriatr Soc 53:374-380, 2005

14. Hess TM: Memory and aging in context. Psychol Bull 131:383-406, 2005

15. Mather M, Carstensen LL: Aging and motivated cognition: the positivity effect in attention and memory. Trends Cogn Sci 9:496-502, 2005

16. Kessels RPC: Patients' memory for medical information. J R Soc Med 96:219-222, 2003

17. Balducci L: Aging, frailty, and chemotherapy. Cancer Control 14:7-12, 2007

18. Extermann M, Hurria A: Comprehensive geriatric assessment for older patients with cancer. J Clin Oncol 25:1824-31, 2007

19. Rodin MB, Mohile SG: A practical approach to geriatric assessment in oncology. J Clin Oncol 25:1936-44, 2007

20. Repetto L, Balducci L: A case for geriatric oncology. Lancet Oncol 3:289-97, 2002

21. Brown SC, Park DC: Theoretical models of cognitive aging and implications for translational research in medicine. Gerontologist 43 Spec No 1:57-67, 2003

22. Rushford N, Murphy BM, Worcester MU, et al: Recall of information received in hospital by female cardiac patients. Eur J Cardiovasc Prev Rehabil 14:463-9, 2007

23. Gattellari M, Butow PN, Tattersall $\mathrm{MH}$, et al: Misunderstanding in cancer patients: why shoot the messenger? Ann Oncol 10:39-46, 1999

24. Butow PN, Brindle E, McConnell D, et al: Information booklets about cancer: factors influencing patient satisfaction and utilisation. Patient Educ Couns 33:129-141, 1998 25. Rost K, Roter D, Bertakis K, et al: Physician-patient familiarity and patient recall of medication changes. The Collaborative Study Group of the SGIM Task Force on the Doctor and Patient. Fam Med 22:453-7, 1990 
Jansen, J., Butow, P.N., Weert, J.C.M. van, Dulmen, S. van, Devine, R.J., Heeren, T.J., Bensing J.M., Tattersall, M.H.N. Does age really matter? Recall for medical information in cancer patients. Journal of Clinical Oncology: 2008, 26(33), 5450-5457

26. Lavelle-Jones C, Byrne DJ, Rice P, et al: Factors affecting quality of informed consent. BMJ 306:885-90, 1993

27. Pesudovs K, Luscombe CK, Coster DJ: Recall from informed consent counselling for cataract surgery. J Law Med 13:496-504, 2006

28. Logan PD, Schwab RA, Salomone JA, 3rd, et al: Patient understanding of emergency department discharge instructions. South Med J 89:770-4, 1996

29. Morrow DG, Weiner M, Young J, et al: Improving medication knowledge among older adults with heart failure: a patient-centered approach to instruction design.

Gerontologist 45:545-552, 2005

30. Brown RF, Butow PN, Dunn SM, et al: Promoting patient participation and shortening cancer consultations: a randomised trial. Br J Cancer 85:1273-1279, 2001

31. Siminoff LA, Graham GC, Gordon NH: Cancer communication patterns and the influence of patient characteristics: disparities in information-giving and affective behaviors. Patient Educ Couns 62:355-360, 2006

32. Eggly S, Penner LA, Greene M, et al: Information seeking during "bad news" oncology interactions: Question asking by patients and their companions. Soc Sci Med 63:2974-2985, 2006

33. Street RL, Millay B: Analyzing patient participation in medical encounters. Health Comm 13:61-73, 2001

34. Street RL, Gordon HS, Ward MM, et al: Patient participation in medical consultations - Why some patients are more involved than others. Med Care 43:960-969, 2005

35. Chouliara Z, Kearney N, Stott D, et al: Perceptions of older people with cancer of information, decision making and treatment: a systematic review of selected literature. Ann Oncol 15:1596-1602, 2004

36. Jansen J, van Weert J, van Dulmen S, et al: Patient education about treatment in cancer care: an overview of the literature on older patients' needs. Cancer Nurs 30:251260, 2007

37. Conill C, Verger E, Salamero M: Performance status assessment in cancer patients. Cancer 65:1864-1866, 1990

38. Spielberger CD: State -Trait Anxiety Inventory (Selfevaluation Questionnaire). Palo

Alto University, California, Consulting Psychologists Press, 1983

39. Sheard T, Maguire P: The effect of psychological interventions on anxiety and depression in cancer patients: results of two meta-analyses. Br J Cancer 80:1770-80, 1999

40. Cassileth BR, Zupkis RV, Sutton-Smith K, et al: Information and participation

preferences among cancer patients. Ann Intern Med 92:832-836, 1980

41. Fox J: Applied regression analysis, linear models, and related methods. London, Sage, 1997

42. Bruera E, Pituskin E, Calder K, et al: The addition of an audiocassette recording of a consultation to written recommendations for patients with advanced cancer: A randomized, controlled trial. Cancer 86:2420-2425, 1999

43. Hack TF, Degner LF, Parker PA: The communication goals and needs of cancer patients: a review. Psychooncology 14:831-45; discussion 846-7, 2005

44. de Haes $\mathrm{H}$ : Dilemmas in patient centeredness and shared decision making: a case for vulnerability. Patient Educ Couns 62:291-298, 2006

45. Back AL, Arnold RM: Discussing prognosis: "how much do you want to know?" talking to patients who are prepared for explicit information. J Clin Oncol 24:4209-4213, 2006

46. Myers L, Derakshan N: To forget or not to forget: What do repressors forget and when do they forget? Cognition Emotion 18:495-511, 2004

47. Shane MS, Peterson JB: Defensive copers show a deficit in passive avoidance learning on Newman's go/no-go task: implications for self-deception and socialization. J Pers 72:939-965, 2004

48. Vos MS, de Haes JC: Denial in cancer patients, an explorative review.

Psychooncology 16:12-25, 2007

49. Ptacek JT, Eberhardt TL: Breaking bad news. A review of the literature. Journal Amer Med Assoc 276:496-502, 1996

50. Leighl N, Gattellari M, Butow P, et al: Discussing adjuvant cancer therapy. J Clin Oncol 19:1768-1778, 2001 
Jansen, J., Butow, P.N., Weert, J.C.M. van, Dulmen, S. van, Devine, R.J., Heeren, T.J., Bensing J.M., Tattersall, M.H.N. Does age really matter? Recall for medical information in cancer patients. Journal of Clinical Oncology: 2008, 26(33), 5450-5457

51. Easterbrook JA: The effect of emotion on cue utilization and the organization of behavior. Psychol Rev 66:183-201, 1959

52. Butow P: Commentary on: The communication goals and needs of cancer patients: a review. Psychooncology. 14:846-847, 2005

53. Clayton JM, Hancock KM, Butow PN, et al: Clinical practice guidelines for communicating prognosis and end-of-life issues with adults in the advanced stages of a life-limiting illness, and their caregivers. Med J Aust 186:S77, S79, S83-108, 2007 54. Neupert SD, McDonald-Miszczak L: Younger and older adults' delayed recall of medication instructions: The role of cognitive and metacognitive predictors. Aging Neuropsychol C 11:428-442, 2004

55. Aapro MS: The frail are not always elderly. J Clin Oncol 23:2121-2122, 2005

56. Morrow D, Leirer VO, Carver LM, et al: Repetition improves older and younger adult memory for automated appointment messages. Hum Factors 41:194-204, 1999

57. Yardley SJ, Davis CL, Sheldon F: Receiving a diagnosis of lung cancer: patients' interpretations, perceptions and perspectives. Palliat Med 15:379-386, 2001

58. Sahay TB, Gray RE, Fitch M: A qualitative study of patient perspectives on colorectal cancer. Cancer Pract 8:38-44, 2000

59. van der Meulen N, Jansen J, van Dulmen S, et al: Interventions to improve recall of medical information in cancer patients: a systematic review of the literature.

Psychooncology, 2007

60. Hack TF, Pickles T, Bultz BD, et al: Impact of providing audiotapes of primary treatment consultations to men with prostate cancer: a multi-site, randomized, controlled trial. Psychooncology 16:543-52, 2007 
Jansen, J., Butow, P.N., Weert, J.C.M. van, Dulmen, S. van, Devine, R.J., Heeren, T.J., Bensing J.M., Tattersall, M.H.N. Does age really matter? Recall for medical information in cancer patients. Journal of Clinical Oncology: 2008, 26(33), 5450-5457

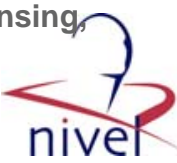

\section{TABLES}

Table 1. Patient and consultation characteristics ${ }^{1}$

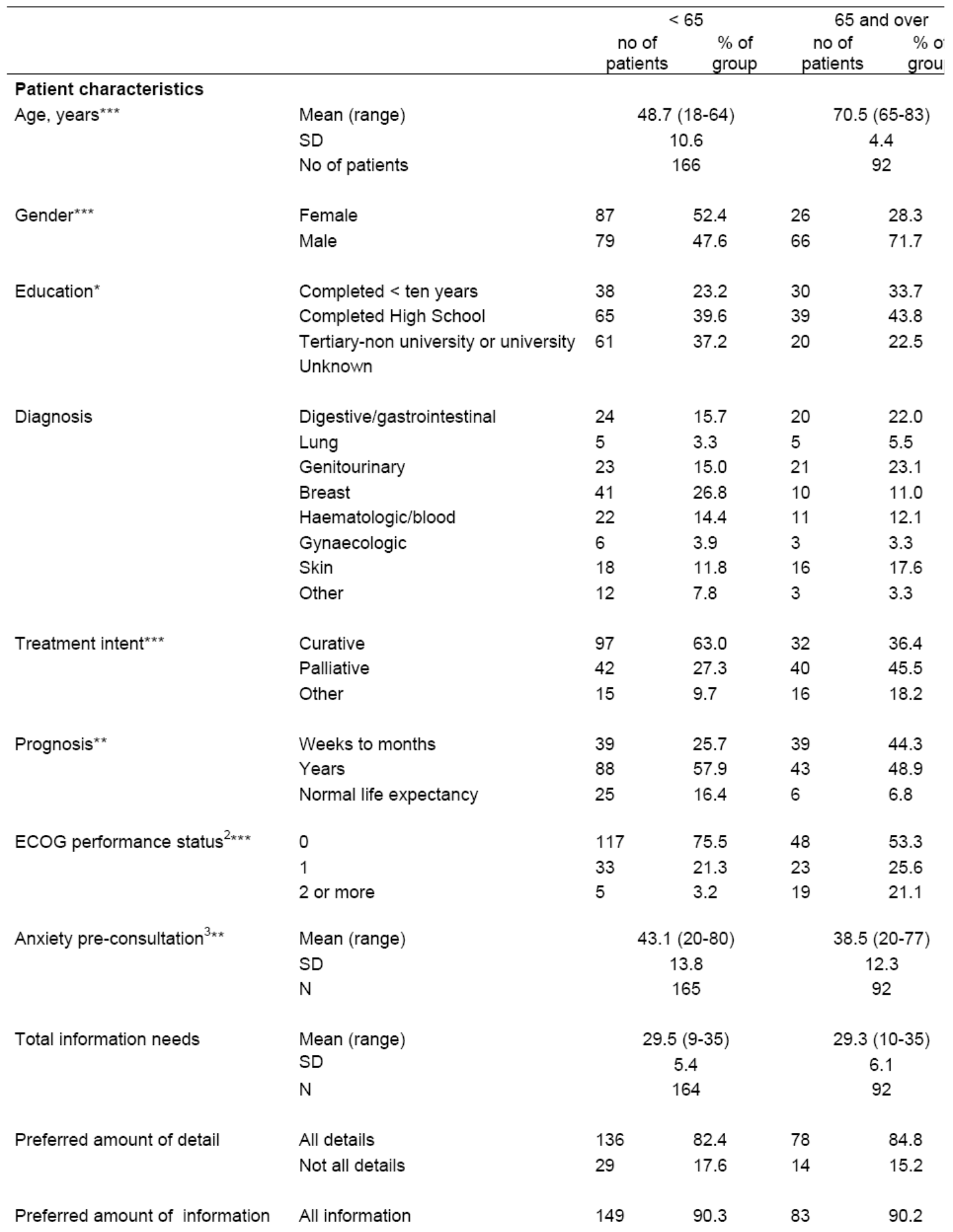


Jansen, J., Butow, P.N., Weert, J.C.M. van, Dulmen, S. van, Devine, R.J., Heeren, T.J., Bensing, J.M., Tattersall, M.H.N. Does age really matter? Recall for medical information in cancer patients. Journal of Clinical Oncology: 2008, 26(33), 5450-5457

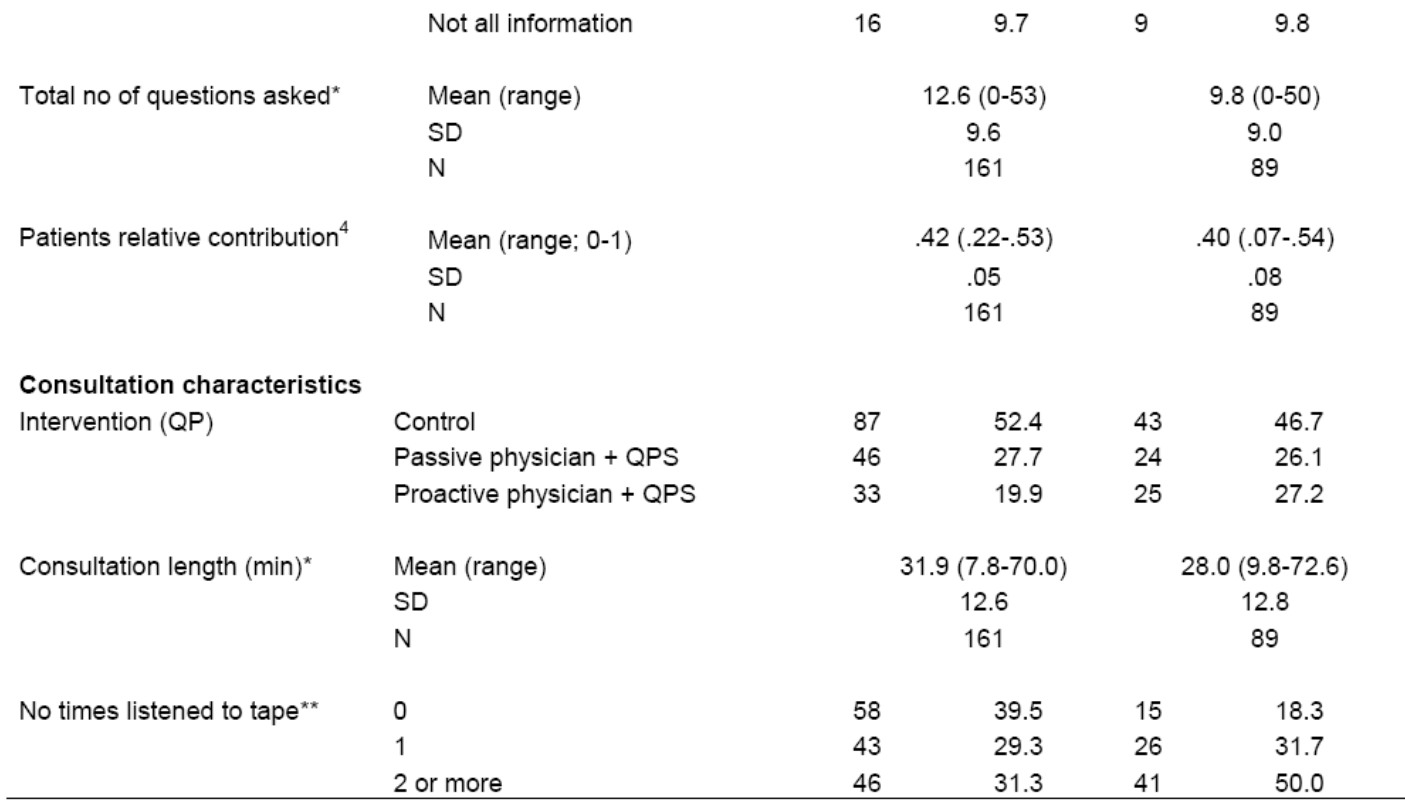

${ }^{1}$ Not all figures add up to 260 patients, due to missing data

${ }^{2} \mathrm{~A}$ higher score indicates poorer performance status

${ }^{3} \mathrm{~A}$ higher score indicates greater anxiety

${ }^{4}$ Patient events / total patient and physician events

${ }^{*} p<0.05$

${ }^{* *} p<0.01$

${ }^{* * *} \mathrm{p}<0.001$ 
Jansen, J., Butow, P.N., Weert, J.C.M. van, Dulmen, S. van, Devine, R.J., Heeren, T.J., Bensing, J.M., Tattersall, M.H.N. Does age really matter? Recall for medical information in cancer patients. Journal of Clinical Oncology: 2008, 26(33), 5450-5457

Table 2. Information discussed, recalled facts and $\%$ recall according to age $(<65$ $n=166 ; \geq 65 n=92)$

\begin{tabular}{|c|c|c|c|c|c|c|c|c|}
\hline \multirow[t]{2}{*}{ Category ${ }^{\star}$} & \multicolumn{2}{|c|}{ Consultations $^{1}(\%)$} & \multicolumn{2}{|c|}{$\begin{array}{l}\text { No of items } \\
(\mathrm{M} /(\mathrm{SD}))^{2}\end{array}$} & \multicolumn{2}{|c|}{$\begin{array}{l}\text { No of items recalled } \\
(M / S D)^{2}\end{array}$} & \multicolumn{2}{|c|}{$\%$ recall $(M /(S D))^{2}$} \\
\hline & $<65$ & $\geq 65$ & $<65$ & $\geq 65$ & $<65$ & $\geq 65$ & $<65$ & $\geq 65$ \\
\hline Total & 100 & 100 & $13.4(4.4)$ & $12.4(4.1)$ & $6.5(3.2)$ & $5.7(2.7)$ & $49.5(20.2)$ & $48.4(22.2)$ \\
\hline Diagnosis & 99.4 & 100 & $1.9(1.1)^{\star}$ & $1.6(.8)$ & $1.1(.8)$ & $1.0(.7)$ & $58.6(37.1)$ & $67.4(38.6)$ \\
\hline Treatment & 98.8 & 100 & $6.4(2.4)$ & $6.4(2.0)$ & $3.3(1.8)$ & $3.2(1.7)$ & $53.5(25.1)$ & $51.9(25.1)$ \\
\hline Prognosis & 91.0 & 83.7 & $2.3(1.1)$ & $2.2(1.2)$ & $.9(.9)$ & $.8(.7)$ & $42.4(37.6)$ & $38.7(38.2)$ \\
\hline Tests & 68.7 & 66.3 & $1.5(.7)$ & $1.4(.7)$ & $.8(.7)$ & $.6(.6)$ & $52.4(44.2)$ & $45.8(41.1)$ \\
\hline Medical oth. & 62.0 & 51.1 & $1.7(1.1)$ & $1.4(.8)$ & $.6(.7)$ & $.4(.6)$ & $36.9(42.2)$ & $30.7(42.7)$ \\
\hline Psychosocial & 54.2 & 44.6 & $1.7(.8)^{\star}$ & $1.4(.5)$ & $.5(.6)^{\star}$ & $.3(.5)$ & $31.2(40.4)$ & $22.0(40.4)$ \\
\hline Help avail. & 13.9 & 18.5 & $1(.0)$ & $1(.0)$ & $.5(.5)$ & $.3(.5)$ & $52.2(51.1)$ & $29.4(47.0)$ \\
\hline
\end{tabular}

${ }^{1}$ The percentage of consultations in which items were discussed, age differences tested using Chi Square statistics (discussed vs. not-discussed).

${ }^{2}$ Calculated over all consultations in which at least one item from the category was discussed

${ }^{*} p<0.05$

${ }^{* *} \mathrm{p}<0.01$

${ }^{* * *} p<0.001$ 
Jansen, J., Butow, P.N., Weert, J.C.M. van, Dulmen, S. van, Devine, R.J., Heeren, T.J., Bensing J.M., Tattersall, M.H.N. Does age really matter? Recall for medical information in cancer patients. Journal of Clinical Oncology: 2008, 26(33), 5450-5457

Table 3. Multiple regression analysis of percentage accurate recall $(n=203)^{1,2,3}$

\begin{tabular}{lcc}
\hline Blocks & \multicolumn{2}{l}{$\%$ recall } \\
\hline & B & SE \\
\hline
\end{tabular}

Intercept

$55.075 \quad 4.755$

Background variables

Gender (female) ${ }^{4}$

$3.085 \quad 2.839$

Education (year 10 or less) ${ }^{4}$

$\begin{array}{lll}\text { year } 12 \text { (HSC) } & 4.584 & 3.315 \\ \text { postgraduate } & -0.044 & 3.917\end{array}$

Age and age-related variables

Age of patient

$-0.249^{*} \quad 0.110$

Prognosis (normal life expectancy) ${ }^{4}$

years

$-10.035^{\star} \quad 4.157$

weeks to months

$-14.224^{\star *} \quad 4.844$

ECOG status $(0)^{4,5}$

1

$3.773 \quad 3.434$

$-3.179 \quad 4.975$

Anxiety pre-consultation

$-0.009 \quad 0.109$

Information needs (total score)

$0.081 \quad 0.248$

Patient participating behaviour

Number of questions asked

$-0.004 \quad 0.172$

Relative patient contribution

$-13.746$

22.497

Consultation characteristics

Total facts

$-0.900^{*} \quad 0.371$

Total facts quadratic, $x^{2}$

$0.123^{*} \quad 0.052$

Consultation length (minutes)

$-0.488^{\star \star}$

0.145

$\mathbf{R}^{2}$ final model

Adjusted $\mathbf{R}^{2}$ final model

${ }^{1}$ The intervention (QP) and number of times listened to the tape were controlled for throughout

${ }^{2}$ The block with interaction terms is not included in this model

${ }^{3}$ All continuous variables were mean centred, thus the intercept can be interpreted as the average recall score of a (hypothetical) subject with scores of ' 0 ' for each predictor in the model ${ }^{4}$ Denotes dummy coded variable with reference group in brackets

${ }^{5} \mathrm{~A}$ higher score indicates poorer performance status

${ }^{6} \mathrm{~A}$ higher score indicates greater anxiety

${ }^{*} p<0.05$

${ }^{* *} p<0.01$

${ }^{* * *} p<0.001$ 
Jansen, J., Butow, P.N., Weert, J.C.M. van, Dulmen, S. van, Devine, R.J., Heeren, T.J., Bensing, J.M., Tattersall, M.H.N. Does age really matter? Recall for medical information in cancer patients. Journal of Clinical Oncology: 2008, 26(33), 5450-5457

Table 4. Information discussed, recalled facts and \% recall according to estimated prognosis (normal $n=32$; years $n=132$; weeks to months $n=78$ )

\begin{tabular}{|c|c|c|c|c|c|c|c|c|c|}
\hline \multirow[b]{2}{*}{$\begin{array}{l}\text { Estimated } \\
\text { prognose }^{2}\end{array}$} & \multicolumn{3}{|c|}{ No of items $(M /(S D))^{1}$} & \multicolumn{3}{|c|}{$\begin{array}{l}\text { No of items recalled } \\
\qquad(M / S D)^{1}\end{array}$} & \multicolumn{3}{|c|}{ Recall $(M /(S D))^{1}$} \\
\hline & normal & years & $\begin{array}{l}\text { weeks to } \\
\text { months }\end{array}$ & normal & years & $\begin{array}{l}\text { weeks to } \\
\text { months }\end{array}$ & normal & years & $\begin{array}{c}\text { weeks to } \\
\text { months }\end{array}$ \\
\hline Total & $\begin{array}{l}12.8 \\
(4.8)\end{array}$ & $\begin{array}{l}12.8 \\
(4.1)\end{array}$ & $\begin{array}{l}13.5 \\
(4.2)\end{array}$ & $\begin{array}{l}7.4^{*} \\
(3.4)\end{array}$ & $\begin{array}{c}6.2 \\
(3.0)\end{array}$ & $\begin{array}{l}5.8 \\
(2.9)\end{array}$ & $\begin{array}{l}60.2^{\star * *} \\
(20.7)\end{array}$ & $\begin{array}{c}49.4 \\
(20.3)\end{array}$ & $\begin{array}{c}43.1 \\
(19.8)\end{array}$ \\
\hline Diagnosis & $\begin{array}{l}2.0^{* *} \\
(1.2)\end{array}$ & $\begin{array}{c}2.0 \\
(1.0)\end{array}$ & $\begin{array}{l}1.5 \\
(.7)\end{array}$ & $\begin{array}{l}1.4^{* *} \\
(1.0)\end{array}$ & $\begin{array}{l}1.1 \\
(.8)\end{array}$ & $\begin{array}{l}.9 \\
(.7)\end{array}$ & $\begin{array}{c}70.0 \\
(32.5)\end{array}$ & $\begin{array}{c}58.3 \\
(36.8)\end{array}$ & $\begin{array}{c}62.4 \\
(42.1)\end{array}$ \\
\hline Treatment & $\begin{array}{c}6.3 \\
(2.5)\end{array}$ & $\begin{array}{c}6.3 \\
(2.1)\end{array}$ & $\begin{array}{c}6.9 \\
(2.4)\end{array}$ & $\begin{array}{c}3.7 \\
(1.9)\end{array}$ & $\begin{array}{c}3.3 \\
(1.7)\end{array}$ & $\begin{array}{c}3.0 \\
(1.8)\end{array}$ & $\begin{array}{l}63.0^{\circ} \\
(26.0)\end{array}$ & $\begin{array}{c}53.8 \\
(23.5)\end{array}$ & $\begin{array}{c}46.1 \\
(24.7)\end{array}$ \\
\hline Prognosis & $\begin{array}{l}2.2^{\prime} \\
(1.0)\end{array}$ & $\begin{array}{c}2.2 \\
(1.1)\end{array}$ & $\begin{array}{l}2.6 \\
(1.2)\end{array}$ & $\begin{array}{l}1.2 \\
(.9)\end{array}$ & $\begin{array}{l}.8 \\
(.8)\end{array}$ & $\begin{array}{l}.9 \\
(.9)\end{array}$ & $\begin{array}{c}55.1 \\
(38.1)\end{array}$ & $\begin{array}{c}39.7 \\
(39.2)\end{array}$ & $\begin{array}{l}36.8 \\
(33.6)\end{array}$ \\
\hline
\end{tabular}

${ }^{1}$ Calculated over all consultations in which at least one item from the category was discussed

${ }^{2}$ Differences were tested using one-way ANOVA's

${ }^{*} p<.05$

** $p<.01$

*** $p<.001$ 